\title{
Effect of Crack Pattern on the Residual Strength of Ceramics After Quenching
}

\author{
Yingfeng Shao, ${ }^{\dagger} \ddagger$ Yue Zhang, ${ }^{\S}$ Xianghong Xu, ${ }^{\ddagger}$ Zhiliang Zhou, ${ }^{\ddagger}$ Wei Li, ${ }^{\ddagger}$ and Boyang Liu \\ * State Key Laboratory of Nonlinear Mechanics (LNM), Institute of Mechanics, \\ Chinese Academy of Sciences, Beijing, 100190, China \\ ${ }^{\S}$ School of Foreign Languages, Harbin Institute of Technology, Harbin, 150080, China \\ "Institute of Marine Materials Science and Engineering, Shanghai Maritime University, Shanghai, 201306, China
}

\begin{abstract}
The physical mechanisms between residual strength and crack characteristic of ceramics after water-quenching are studied by statistically measuring the cracks in ceramic sheet. The result herein reveals that in the joint action of long crack length and density, the residual strength is maintained at the same level within a temperature range above the critical thermal shock temperature difference $\left(\Delta T_{\mathrm{C}}\right)$. The result presented herein forms a further comprehension to the ceramics behaviors of and the theoretical approaches to thermal shock.
\end{abstract}

\section{Introduction}

$\mathrm{T}$ HERMAL shock behavior of dense ceramics typically exhibits four stages in thermal shock testing (Fig. 1). ${ }^{1-3}$ In the first regime (regime I), quenched specimens show no strength degradation compared with unquenched ones; In the second regime (regime II), the specimens show a sharp drop in strength because the stresses generated during quenching are higher than those required for crack initiation. In the third regime (regime III), the residual strength maintained unchanged at a certain temperature difference range, and then the residual strength decreased gradually until the final fracture as the temperature difference increases (regime IV).

To investigate the damage mechanism of ceramic in thermal shock, Davidge used the cutting specimens method to observe interior cracks, and found that when temperature difference was greater than $\Delta T_{\mathrm{C}}$, within regime III and IV, the long crack depth would gradually increase and accompany a decline in residual strength of the sample. ${ }^{4}$ However, based on systematic research on thermal shock theory, ${ }^{3,5,6}$ Hasselman considered that when temperature difference was in regime III, the crack depth, as well as residual strength was not changed. ${ }^{5}$ After Hasselman, ${ }^{5}$ Bahr who found that crack depth was increased with $\Delta T$ in a long strip by energy release rate calculation, ${ }^{7}$ got a result similar to Davidge. ${ }^{4}$ So, to identify the damage mechanism and to develop the theoretical approach of thermal shock, it is necessary to clarify the relationship between crack characteristics and corresponding residual strength within regime III. The basic idea is to quench the ceramic sheet, since the problem of thin sample suffering from thermal shock can be considered as

Z.-H. Jin—contributing editor

Manuscript No. 29553. Received April 04, 2011; approved June 09, 2011.

This work was supported by the National Natural Science Foundations of China (Grant. 11061130550, 11021262, 11023001 and 10802087) and Imech Innovation Program in 2010 .

${ }^{\dagger}$ Author to whom correspondence should be addressed. e-mail: shaoyf@Inm.imech. ac.cn plane stress, and the influence of the stress produced in thin dimension on crack can be avoided.

In the present study, we experimentally reveal the crack characteristics of ceramic sheet after quenching in water. By comparing the crack patterns within a temperature range above $\Delta T_{\mathrm{C}}$, we further point out the influences of the long crack depth and density on the residual strength.

\section{Experimental Procedure}

\section{(1) Materials Processing}

The ceramic studied and reported herein was made of $\mathrm{Al}_{2} \mathrm{O}_{3}$ powder (particle size $0.5 \mu \mathrm{m}$; Xiongdi Material Co., Jiyuan, China), which was uniaxially pressed at $20 \mathrm{MPa}$ into pellets and subsequently sintered at $1650^{\circ} \mathrm{C}$ for $2 \mathrm{~h}$ without pressure. The porosity of the ceramics was about $4 \%$ by calculation from measured dimension and weight.

\section{(2) Thermal Shock Test}

Ceramic sheet with dimensions of $1.0 \mathrm{~mm}$ in width, $9.8 \mathrm{~mm}$ in thickness and $50 \mathrm{~mm}$ in length were employed to investigate the crack patterns after thermal shock by the conventional water-quenching technique. To prevent access of the coolant to the side faces, the sheet was stacked with four other ceramic slabs, and was bound up with inconel wires $(0.4 \mathrm{~mm}$ in diameter; Shanghai New Soviet China Special Alloy Material Co., Shanghai, China) positioned $<4 \mathrm{~mm}$ from both the ends of the slabs, as shown in Fig. 2.

The specimens were heated at a rate of $10^{\circ} \mathrm{C} / \mathrm{min}$ to a preset temperature and held at this temperature for $20 \mathrm{~min}$.

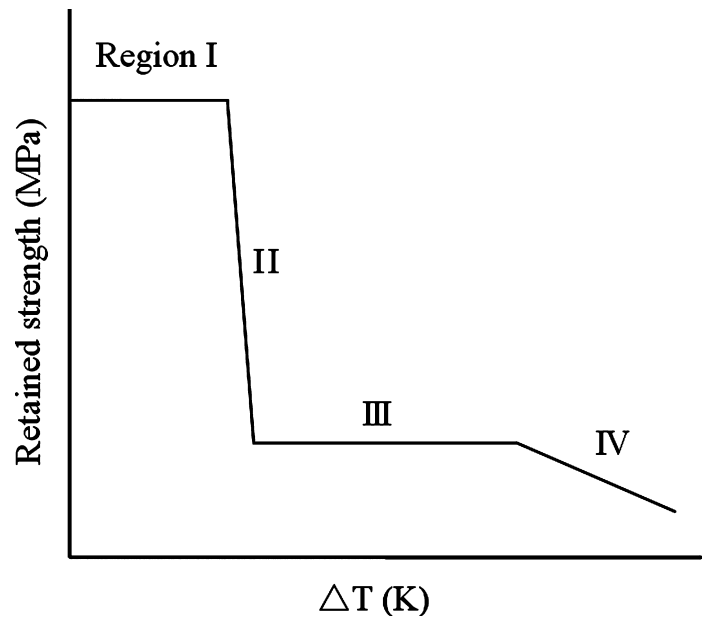

Fig. 1. Regimes of thermal shock damage as a function of the quench temperature as characterized by residual flexural strength. 


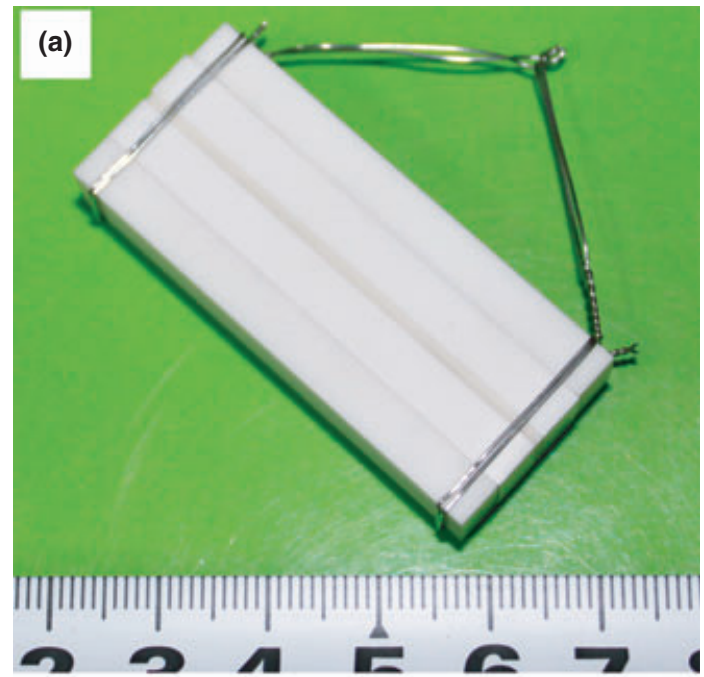

(b)

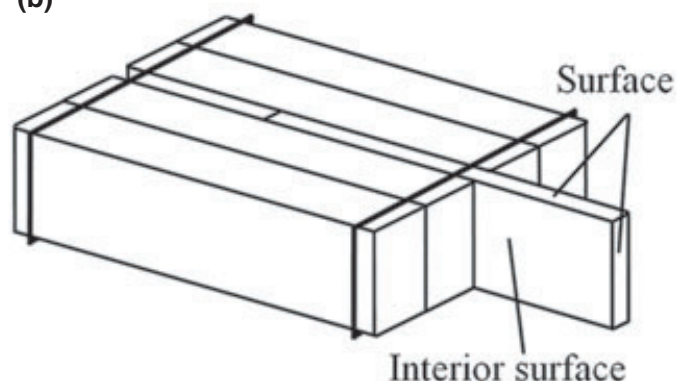

Fig. 2. (a) Stacked samples prepared for thermal shock; (b) The definitions of the surface and the interior surface of the sheets.

After that, the heated plate specimens were dropped by free fall into a water bath that was maintained at $20^{\circ} \mathrm{C}$ with a thermostat for $10 \mathrm{~min}$ taken out and dried at $80^{\circ} \mathrm{C}$ for $2 \mathrm{~h}$, the specimens were then impregnated with a blue dye (Shanghai Ink Factory, Shanghai, China) for the purpose of observing the cracks that formed during thermal shock. Both the surface and the interior crack patterns were studied by using digital scanning.

Four specimens were chosen to examine the depth and density of cracks at every temperature difference. Note that, the crack patterns appearing within $10 \mathrm{~mm}$ from both ends of each specimens are excluded for the sake of eliminating boundary effects.

The residual strengths of the quenched specimens were determined in a three-point bending test with a support span of $30 \mathrm{~mm}$ and a cross-head speed of $0.5 \mathrm{~mm} / \mathrm{min}$. For comparison, the fracture strengths of the unquenched specimens were also measured under the same conditions as those of the quenched specimens. Four specimens were tested to obtain the average strength.

\section{(3) Finite Element Model for Calculating Residual Strength}

The mode I stress intensity factor $K_{\mathrm{I}}$ was used to determine the residual strength of specimen with cracks, when it reached the critical stress intensity factor $K_{\mathrm{IC}}$. For the specimen with equally spaced parallel edge cracks, subjected to the three-point flexure it was calculated using the displacement method embedded in the ANSYS code using the command "KCALC." A representative mesh is shown in Fig. 3, along with the appropriate boundary conditions. Analyses were performed by a 2D plane stress FE model with higher order 8-node quadrilateral elements. Crack tip singularity elements transformed from the conventional quadrilaterals by moving the mid-nodes to quarter point are used around the crack tip.

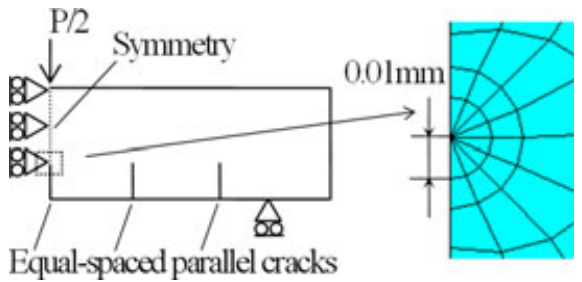

Fig. 3. Finite element model used to determine $K_{\mathrm{I}}$ for the threepoint flexure specimen and the crack tip elements.

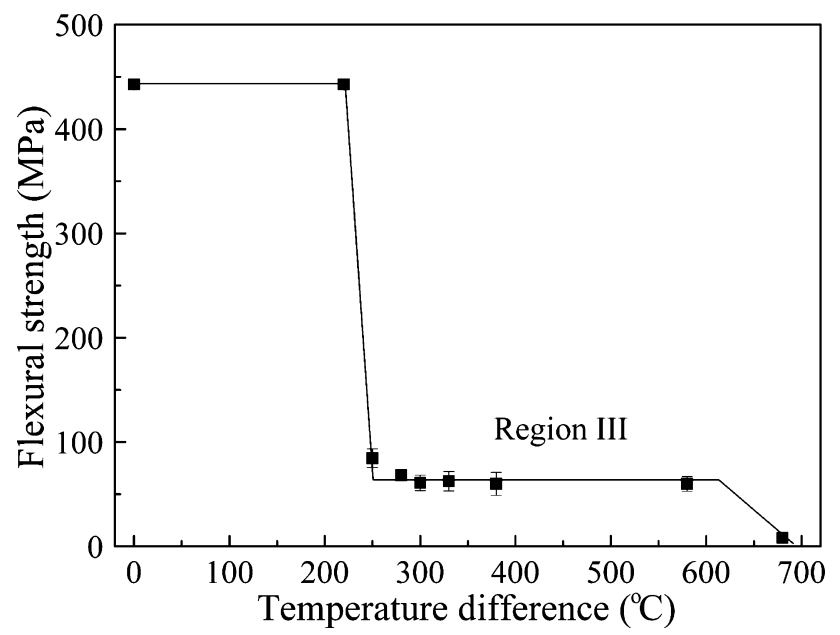

Fig. 4. Strength as a function of quenching temperature difference for alumina sheet.

\section{Results and Discussion}

The strength behavior of the alumina as a function of quenching temperature difference, $\Delta T$, was shown in Fig. 4. The residual strength of the quenched specimens decreased acutely from 443 to $84 \mathrm{MPa}$ when $\Delta T$ increased from $220^{\circ} \mathrm{C}$ to $250^{\circ} \mathrm{C}$. However, the residual strength remained on the same level with $\Delta T$ increasing from $280^{\circ} \mathrm{C}$ to $580^{\circ} \mathrm{C}$, indicating regime III of thermal shock behavior. This phenomenon agrees in general with the expected behavior (Fig. 1) discussed in Section I.

Thermal shock cracks occurred on the interior surfaces of sheet only when the temperature difference between the ceramic sheet and water bath was greater than critical temperature difference of about $230 \mathrm{~K}$. The number of the crack increased with the increase of $\Delta T$, as shown in Fig. 5. In detail, when $230 \mathrm{~K}<\Delta T<250 \mathrm{~K}$, there were only sparse cracks on the surface of the sheets, and it was in agreement with our previous work in $\mathrm{Al}_{2} \mathrm{O}_{3}$ slabs; ${ }^{8}$ when $\Delta T \approx 280 \mathrm{~K}$, a hierarchical structure of short and long cracks began to occur, ${ }^{9}$ and the crack structure became to have three different penetration depths as $\Delta T \approx 380 \mathrm{~K}$, which was consistent with the result reported by Jenkins in a shrinking slab; ${ }^{10}$ then the crack density increased as $\Delta T$ further enhanced, and finally when $\Delta T \approx 680 \mathrm{~K}$, through-thickness cracks appeared in the sheet which meant the complete damage of the ceramic.

Crack depth distributions of ceramic sheet after thermal shock at different temperatures are provided in Fig. 6. As is shown, the number of cracks that increased with $\Delta T$, indicated the increase of damage extent. Then, when $\Delta T$ was larger than $250 \mathrm{~K}$, a short crack $(<0.1)$ appeared and it had sharp increased trend with $\Delta T$. In addition, the cracks can be roughly divided into three types by depth, the short crack, the medium, and the long crack, respectively. Based on statistical data, we further defined the crack that was greater than $30 \%$ of sample thickness as the long crack. The variations in density and depth of the long crack with different $\Delta T$ quenched in water are shown in Table I. Long crack 


\section{(a)}
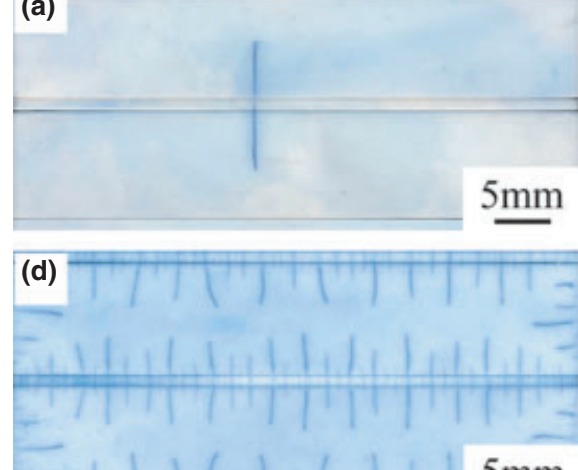

$5 \mathrm{~mm}$ (b)

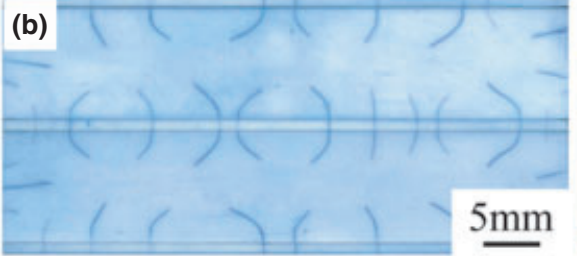

(e)

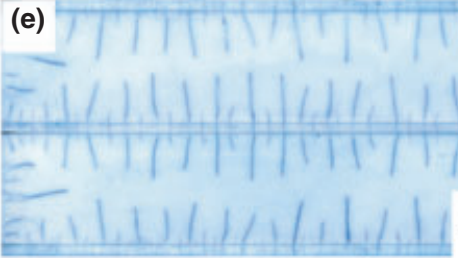

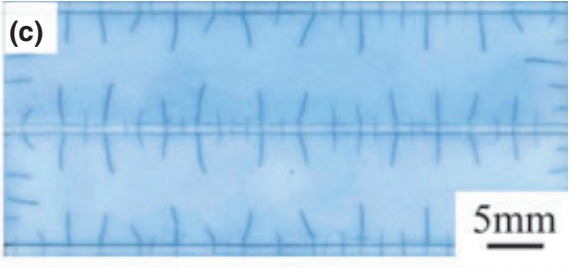

(f)

Fig. 5. Thermal shock crack patterns on the interior surfaces of the sheet quenched in water at $\Delta T$ of (a) $230 \mathrm{~K}$; (b) $250 \mathrm{~K}$; (c) $280 \mathrm{~K}$; (d) $380 \mathrm{~K}$; (e) $580 \mathrm{~K}$; (f) $680 \mathrm{~K}$, where narrow bands stand for the surfaces and wide bands show the interior surfaces.

(a)

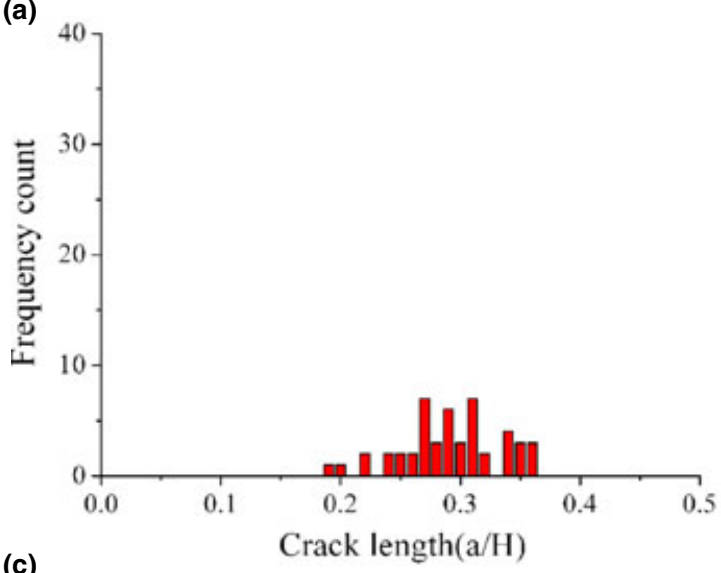

(c)

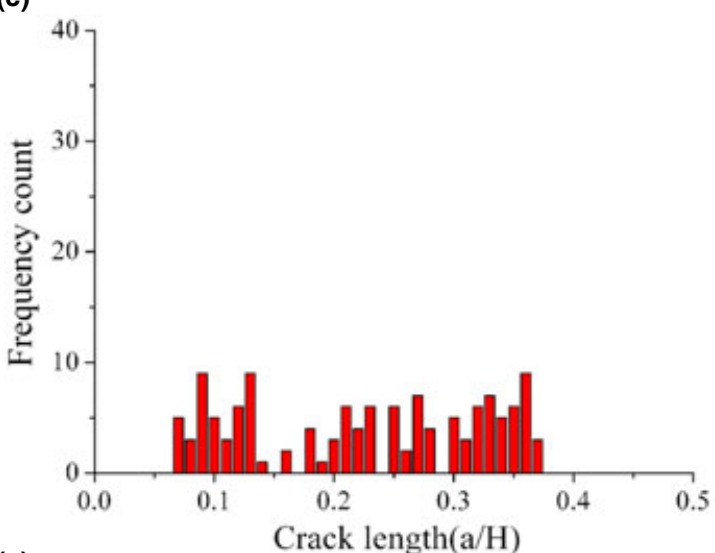

(e)

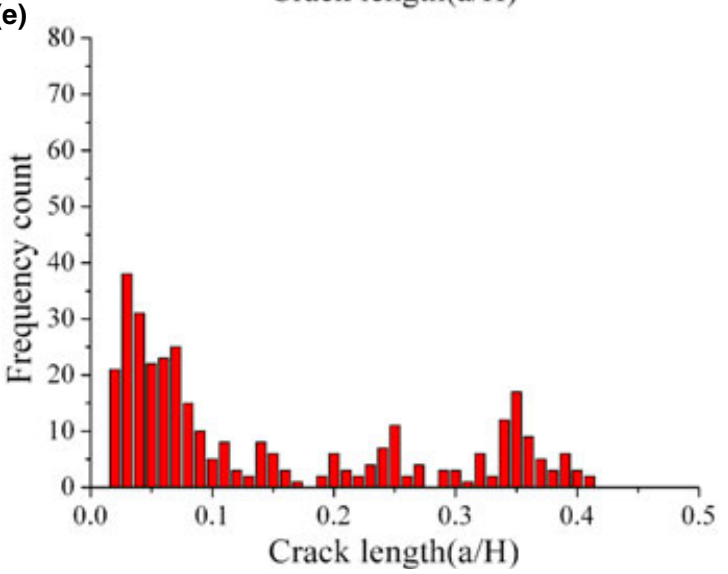

(b)

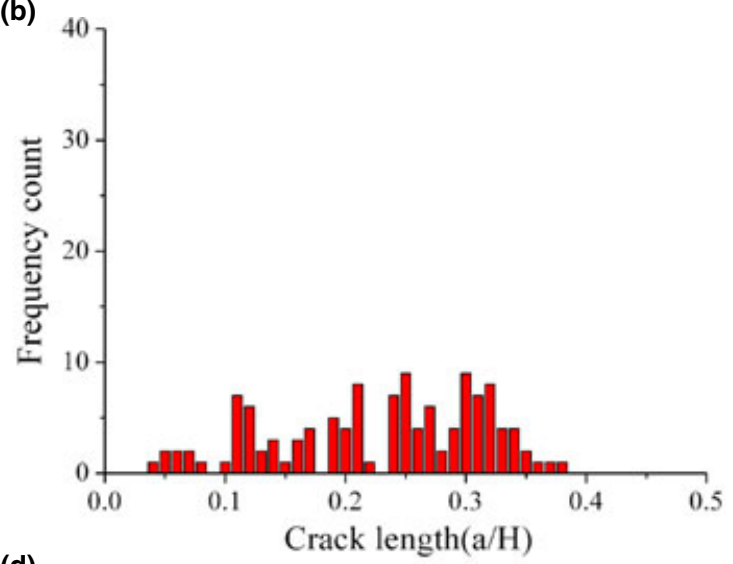

(d)

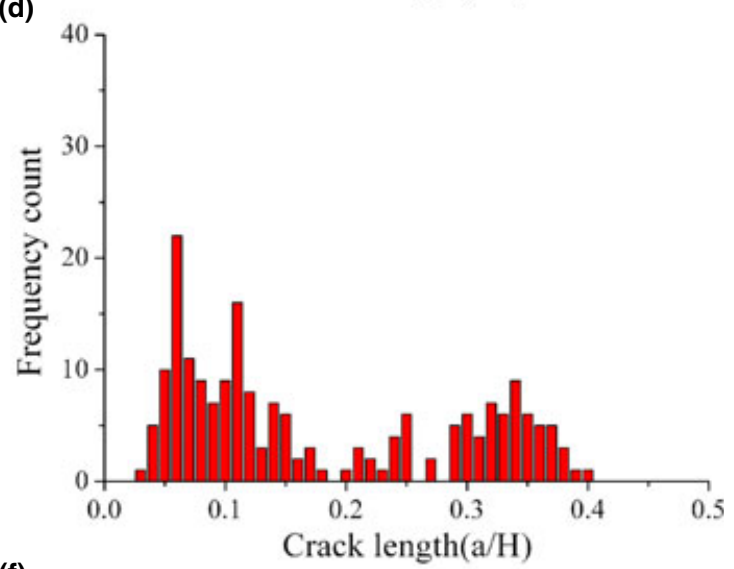

(f)

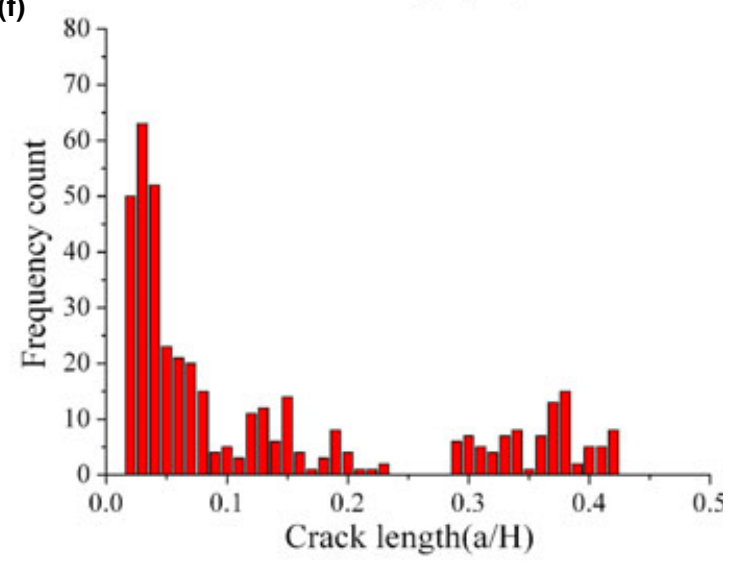

Fig. 6. Dimensionless crack depth $(a / H)$ distributions obtained by using quantitative image analysis of the sheet quenched in water at $\Delta T$ of (a) $250 \mathrm{~K}$; (b) $280 \mathrm{~K}$; (c) $300 \mathrm{~K}$; (d) $330 \mathrm{~K}$; (e) $380 \mathrm{~K}$; (f) $580 \mathrm{~K}$, where $a$ is the real crack depth and $H$ is the thickness of ceramic sheet. 
Table I. Long Crack Depth and Density of Ceramic Sheet Quenched in Water at Different $\Delta T$

\begin{tabular}{lcccccc}
\hline$\Delta T$ & $250 \mathrm{~K}$ & $280 \mathrm{~K}$ & $300 \mathrm{~K}$ & $330 \mathrm{~K}$ & $380 \mathrm{~K}$ & $580 \mathrm{~K}$ \\
\hline Long crack depth & $0.326 \pm 0.019$ & $0.334 \pm 0.028$ & $0.342 \pm 0.026$ & $0.351 \pm 0.022$ & $0.366 \pm 0.029$ & $0.373 \pm 0.021$ \\
Count & 22 & 37 & 44 & 53 & 69 & 87 \\
\hline
\end{tabular}

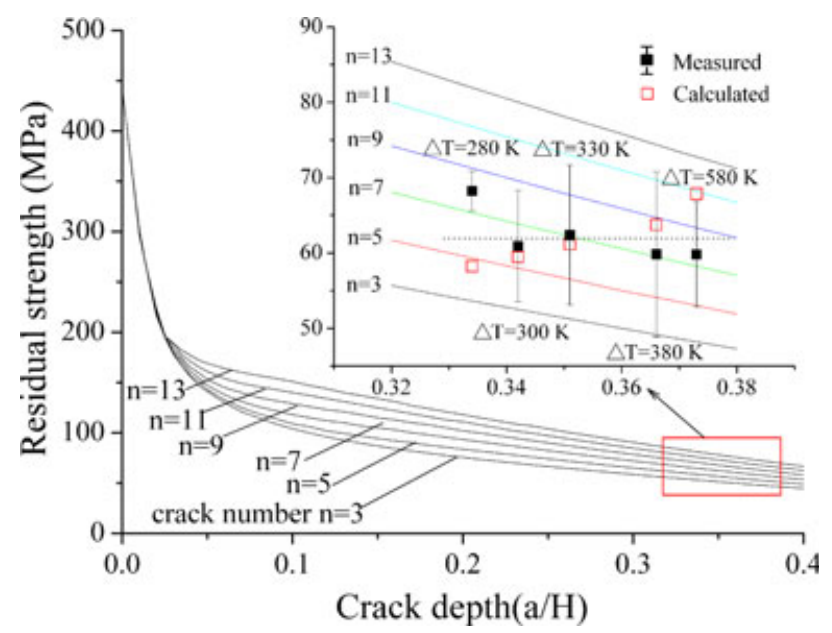

Fig. 7. Residual strength as a function of crack depth and crack density corresponded to three-point flexure by FEM and comparison with the test measured.

depth of specimens were $0.326,0.334$, and 0.373 in the case of $\Delta T=250 \mathrm{~K}, \Delta T=280 \mathrm{~K}$, and $\Delta T=580 \mathrm{~K}$, respectively. It revealed that the crack depth increased gradually with $\Delta T$, and an increase of $11.7 \%$ is presented from $\Delta T=280 \mathrm{~K}$ to $\Delta T=580 \mathrm{~K}$, which was similar to what was reported by Davidge et al. in $\mathrm{Al}_{2} \mathrm{O}_{3}$ slabs. ${ }^{4}$ Furthermore, like crack density, long crack density was also increased with $\Delta T$, and the crack number increased from 37 to 87 (about 2.4 times) with the $\Delta T$ range from $280 \mathrm{~K}$ to $580 \mathrm{~K}$.

The prediction of brittle fracture in cracked solids based on the stress intensity factor $K_{\mathrm{I}}$ of linear elastic fracture mechanics is widely accepted. ${ }^{11} \mathrm{~A}$ representation of the evolution of residual strength corresponding to $K_{\mathrm{I}}$ as a function of long crack density and depth is given in Fig. 7. We observed that the residual strength gradually decreased with long crack depth, but the trend was reversed corresponding to crack density. Note that, in the present test, although the crack depth of specimens after thermal shock in regime III had some differences, ranging from 0.33 to 0.38 , the calculated residual strength was roughly on the same level as well as the measured one indicated in Fig. 4.

From the view point of fracture mechanics, the crack density increase can reduce the stress intensity factor at the crack tip under the same load, ${ }^{12}$ so that the residual strength of samples is increased. However, the influence of crack depth on residual strength of samples is opposite compared with crack density. Therefore, the influence of long crack depth and density on residual strength offset each other to some extent. Note that, the influence of other cracks on residual strength was excluded as specimen residual strength is mainly dependent on deep cracks. 4

\section{Conclusions}

In conclusion, thermal shock testing in the temperature range higher than $\Delta T_{\mathrm{C}}$ shows that the depth of long crack is gradually increased, but the increase rate is not very pronounced. In addition, the long crack density gradually increased also, and the increment is much more obvious than the crack depth. As a result, the influence of long crack depth and density on residual strength offset each other to some extent, so the residual strength of the specimens remains essentially unchanged.

\section{References}

${ }^{1}$ A. A. Buchheit, G. E. Hilmas, W. G. Fahrenholtz, and D. M. Deason, "Thermal Shock Resistance of an AlN-BN-SiC Ceramic," J. Am. Ceram. Soc., 92 [6] 1358-61 (2009).

${ }^{2}$ W. E. Pompe, "Thermal Shock Behavior of Ceramic Materials-Modelling and Measurement"; pp. 3-14 in Thermal Shock and Thermal Fatigue Behavior of Advanced Ceramics. Edited by G. A. Schneider and G. Petzow. Kluwer Academic Publishers, Netherlands, 1993.

${ }^{3}$ D. P. H. Hasselman, "Strength Behavior of Polycrystalline Alumina Subjected to Thermal Shock," J. Am. Ceram. Soc., 53 [9] 490-5 (1970).

${ }^{4}$ R. W. Davidge and G. Tappin, "Thermal Shock and Fracture in Ceramics," Trans. Br. Ceram. Soc., 66 [8] 405-22 (1967).

${ }^{5}$ D. P. H. Hasselman, "Elastic Energy at Fracture and Surface Energy as Design Criteria for Thermal Shock,"J. Am. Ceram. Soc., 46 [11] 535-40 (1963).

${ }^{6}$ D. P. H. Hasselman, "Unified Theory of Thermal Shock Fracture Initiation and Crack Propagation in Brittle Ceramics," J. Am. Ceram. Soc., 52 [11] 6004 (1969).

${ }^{7}$ H. A. Bahr, H. J. Weiss, H. G. Maschke, and F. Meissner, "Multiple Crack Propagation in a Strip Caused by Thermal Shock," Theor. Appl. Fract. Mech., 21 [1] 2716-20 (1986).

${ }^{8}$ Y. F. Shao, X. H. Xu, S. H. Meng, G. H. Bai, C. P. Jiang, and F. Song, "Crack Patterns in Ceramic Plates After Quenching," J. Am. Ceram. Soc., 93 [10] 3006-8 (2010).

${ }^{9}$ H. A. Bahr, G. Fischer, and H. J. Weiss, "Thermal-Shock Crack Patterns Explained by Single and Multiple Crack Propagation," J. Mater. Sci., 21 [1] 2716-20 (1986).

${ }^{10}$ D. R. Jenkins, "Optimal Spacing and Penetration of Cracks in a Shrinking Slab,” Phys. Rev. E, 71 [5] 056117, 8pp (2005).

${ }^{11}$ M. L. Dunn, W. Suwito, and S. Cunningham, "Fracture Initiation at Sharp Notches: Correlation Using Critical Stress Intensities," Int. J. Solids Struct., 34 [29] 3873-83 (1997).

${ }^{12}$ Z. H. Jin and Y. Z. Feng, "Effects of Multiple Cracking on the Residual Strength Behavior of Thermally Shocked Functionally Graded Ceramics," Int. J. Solids Struct., 45 [24] 5973-86 (2008). 